\title{
EL ROL DE LOS ARCHIVOS EN LA MODERNIZACIÓN DE LA ADMINISTRACIÓN PÚBLICA
}

\author{
Luis Guillermo Núñez Soto* \\ Universidad Católica Sedes Sapientiae \\ lnunez@ucss.edu.pe
}

Fecha de recepción: agosto de 2020 Fecha de aceptación: diciembre de 2020

Resumen: El presente artículo aborda el proceso de modernización de la Administración Pública en nuestro país, vinculado principalmente con la transparencia y acceso a la información, la rendición de cuentas, la lucha contra la corrupción, el gobierno y datos abiertos, así como el rol sustancial que deben cumplir los archivos, ante la importancia de contar con archivos organizados para coadyuvar en ese proceso de modernización y democratización de la sociedad. El estudio de los archivos en la Administración Pública nos revela un problema de gestión de los archivos que requiere pronta atención para contar con un sistema de gestión de archivos moderno que revierta su situación actual. De ese modo, permitirá que los archivos cumplan con la misión de conservar y proporcionar los documentos que brinden información indispensable para el desarrollo de

Luis Guillermo Núnez Soto es magíster en Administración Pública por la Universidad Católica Sedes Sapientiae. Se desempeña como docente asociado de la Facultad de Letras y Ciencias Humanas de la UNMSM a cargo de las materias de Archivística y Conservación Documental e imparte clases en la carrera de Archivística y Gestión Documental de la UCSS. Investigación: código ORCID 0000-0002-7886-6600. 
las actividades de los ciudadanos, instituciones, gobiernos y la sociedad en general, estableciendo la relevancia de los archivos para el acceso y transparencia de la información con el fortalecimiento del Sistema Nacional de Archivos y del Archivo General de la Nación.

Palabras clave: Administración Pública, archivos, transparencia de la información, acceso a la información, Sistema Nacional de Archivos.

\section{THE ROLE OF ARCHIVES IN THE MODERNIZATION OF PUBLIC ADMINISTRATION}

Abstract: This article addresses the modernization process of the Public Administration in our country, mainly linked to transparency and access to information, accountability, the fight against corruption, government and open data, as well as the substantial role that They must comply with the archives, given the importance of having organized archives to assist in this process of modernization and democratization of society. The study of archives in the Public Administration reveals a file management problem that requires prompt attention in order to have a modern archives management system that will reverse its current situation. In this way, it will allow the archives to fulfill the mission of preserving and providing documents that provide essential information for the development of the activities of citizens, institutions, governments and society in general, establishing the relevance of the archives for access and transparency of information with the strengthening of the National Archives System and the General Archives of the Nation.

Keywords: Public Administration, archives, transparency of information, access to information, National Archives System. 


\section{Introducción}

Dodemos afirmar que la Administración Pública se encuentra en permanente modernización, sin embargo, los ciudadanos no perciben que las mejoras en los servicios públicos, pues su modernización es muy lenta. Actualmente se van informatizando los servicios y los portales de las organizaciones públicas ofrecen una serie de servicios. A pesar de ello, aún son incipientes si tenemos en cuenta el desarrollo tecnológico que existe actualmente y todas las posibilidades que ofrece en la gestión de la información.

En este contexto surge la inquietud por realizar el estudio del rol de los archivos en el proceso de modernización de la Administración Pública. Bien es sabido que a dicho conjunto de organismos del Estado se le vincula con aspectos sustanciales como la transparencia y acceso a la información, la rendición de cuentas, la lucha contra la corrupción, el gobierno y datos abiertos $y$, al igual que los archivos, deben cumplir con los requerimientos de información de los ciudadanos y de la sociedad en su conjunto. De ahí la importancia de contar con archivos organizados para coadyuvar en ese proceso de modernización y de democratización de la sociedad.

En el Perú, durante las últimas dos décadas se han aprobado leyes sobre la transparencia y acceso a la información, rendición de cuentas, gobierno abierto y modernización del Estado. Sin embargo, siendo los archivos elementos sustanciales del acceso a la información, no son incorporados en las leyes de acuerdo a lo que nos muestra la investigación desarrollada. La legislación peruana vigente establece la protección de los archivos de la Administración Pública, no obstante, la realidad no concuerda con el mandato legal. El análisis de la situación crítica de los archivos, indica un problema de gestión. Además, observamos presupuestos insuficientes, 
locales inadecuados e improvisación en quiénes asumen la conducción de los archivos, entre otros aspectos.

Existe la necesidad de contar con sistemas de gestión de archivos modernos que revierta la situación. Hacerlo permitirá que estos cumplan su misión de conservar y servir los documentos, con información indispensable para el desarrollo de las actividades de los ciudadanos, instituciones, gobiernos y la sociedad en general. Por lo tanto, se precisa identificar las condiciones que conduzcan a establecer mejoras en la gestión de los archivos públicos. Entre tales aspectos a mejorar se encuentran la legislación archivística y normatividad técnica, la modernización de los archivos públicos, el Sistema Nacional de Archivos (SNA) y el Archivo General de la Nación (AGN).

\section{Metodología}

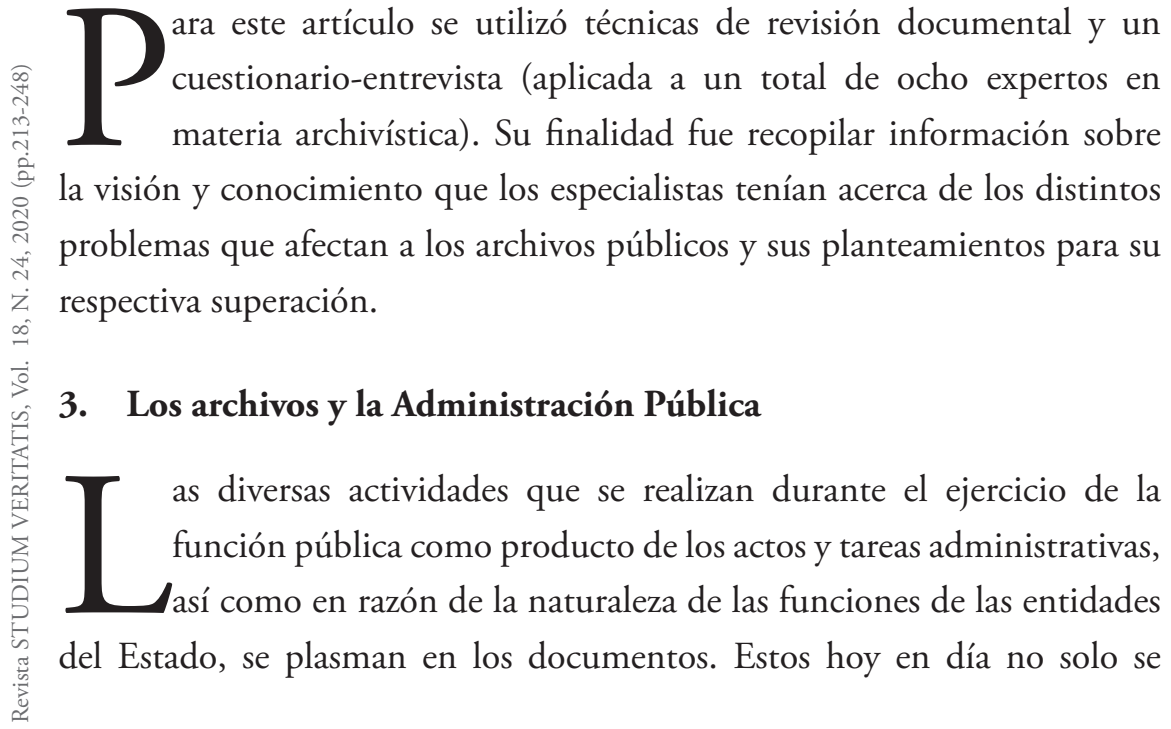


encuentran en papel o "documentos tradicionales" (como usualmente son denominados). Su disponibilidad se da ahora en otros soportes como los que ofrece la tecnología informática y digital.

Todos forman parte del acervo documentario de las organizaciones públicas, de manera que la función pública se mueve en gran medida sobre los documentos que crecen día a día y se acumulan en los archivos públicos. Ampudia (1988) señala que al no existir acción alguna en la Administración Pública que no termine en un documento, entonces tenemos un aparato que produce documentos y archivos a gran escala. Basta tener una visión retrospectiva para comprobar que, sin importar período, época o lugar, siempre que ha existido organización gubernamental de cualquier tipo han existido archivos producidos y usados por ella. De allí que pueda hablarse de documentos y archivos públicos, en cualquier tiempo y lugar, así como en diferentes soportes según la época.

En relación con lo anterior, Nazar refiere que:

Tanto la información como el Estado son fenómenos históricos contemporáneos mutuamente relacionados. La institución estatal es, entre otras cosas, productora de información y administradora principal de lo que generan otras fuentes informativas en tanto es receptora, ordenadora y difusora de las informaciones. Desde esta perspectiva, la importancia de los archivos radica en ser los repositorios elementales de los documentos, soportes de la información; mientras que la relevancia de las instituciones archivísticas se manifiesta en el hecho de ser las responsables de su funcionamiento y cohesión. (2014, p. 13) 
Efectivamente, la historia nos muestra que los archivos se formaron por la acumulación de los documentos generados por las organizaciones gubernamentales y privadas, para luego integrar el patrimonio cultural de los pueblos. Los templos y los palacios de las antiguas civilizaciones eran los lugares por excelencia para la constitución de estos depósitos. Con el surgimiento de Grecia y Roma, los archivos no solo son guardados en los palacios, sino que adquieren la categoría de documentos públicos y se deben a los ciudadanos (Cruz Mundet, 2001). En la Edad Media, los archivos pasan a constituirse en verdaderos "tesoros", pues garantizan los derechos patrimoniales de los monarcas y señores feudales, por lo que son debidamente custodiados en conventos y monasterios. Al llegar al período de las monarquías absolutas (Edad Moderna), los archivos son fuente de poder de los Estados y garantía de sus posesiones territoriales. Por tanto, su consulta o conocimiento solo es accesible a la nobleza y funcionarios que el monarca autorice.

Dicha condición se modifica a partir de la propagación de los ideales de la Revolución Francesa, trayendo como consecuencia que los archivos de Estado se conviertan en nacionales, con la doble finalidad de servir al pueblo y facilitar la labor académica y científica de la historia. Con ello, los archivos quedarán impregnados por mucho tiempo de la idea que solo guardan documentos históricos. A mediados del siglo XX, esta concepción comienza a ser revisada a razón de los avances de la archivística norteamericana, que establece la existencia un ciclo vital del documento y, por lo tanto, aquellos que son de archivo se constituyen desde el momento de su generación o tramitación, determinándose la existencia de archivos administrativos y archivos históricos. 
La historia de los archivos es más reciente en nuestro país. Esta se inicia con el primer documento manuscrito que se custodia en el AGN: el Protocolo Ambulante o Libro de los Conquistadores, que data de 1533. En él se registra los actos realizados por los conquistadores durante la travesía que iniciaron en el norte del país. Los primeros archivos están constituidos por los repositorios de las instituciones virreinales o coloniales, como el Superior Gobierno, la Real Audiencia, el Tribunal de Cuentas, los cabildos, etc. Así queda establecida la importancia de los archivos a través del tiempo. Estos responden a una institucionalidad de la Administración Pública a la cual se le ha encomendado un conjunto de funciones y acciones en una compleja estructura, la cual debe estar acorde con la normatividad establecida para el cumplimiento de los fines de los gobiernos de turno.

En toda actividad de la Administración Pública se producen documentos que registran sus acciones, informan de sus resoluciones y son testimonio de su accionar en un determinado asunto. Estos documentos que calificaremos de archivo- están dados en un proceso (de producción o creación de documentos, gestión, servicio y conservación), donde intervienen dos estamentos: primero, la entidad productora a través de su sistema de archivo como parte de un aparato institucional; y segundo, el órgano archivístico (AGN) responsable de uniformar la gestión de los documentos, así como de la preservación y accesibilidad al patrimonio documental de un país. La misión de los archivos es preservar los documentos para la investigación histórica, la gestión y la memoria de las organizaciones como productores de ellos y lograr que los ciudadanos puedan hacer efectivos sus derechos.

De allí que es importante tener claro y preciso el concepto de archivo, el rol de los archivos públicos y fundamentalmente entender cómo 
el ciclo vital del documento nos ayuda a establecer las bases de la gestión documental y la del sistema institucional de los archivos. Heredia, quien acuña una de las definiciones más interesantes sobre los archivos, pues pone énfasis en la constitución de testimonios y de fuentes para la historia:

Archivo es uno o más conjuntos de documentos, sea cual sea su fecha, su forma y soporte material, acumulados en un proceso natural por una persona o institución pública o privada en el transcurso de su gestión, conservados, respetando aquel orden, para servir como testimonio e información para la persona o institución que los produce, para los ciudadanos o para servir de fuentes de historia. (1993, p. 89)

Por su parte, Cruz Mundet (2011) define al archivo como aquel "Sistema corporativo de gestión que contribuye de manera efectiva mediante una metodología propia a la definición de los procesos de producción administrativa, garantizando la correcta creación de los documentos, su tratamiento, conservación, acceso y comunicación" (p. 78). Vemos claramente que en aquella definición se enfatiza la noción de sistema, la gestión de los documentos y la existencia de procesos propios de la archivística, los que se aplican desde la creación de los documentos hasta su destino final.

Los documentos de los archivos públicos son conservados y tratados de acuerdo con la legislación que existe sobre la materia por todas las organizaciones públicas. Estos no solo se usan como medios probatorios, sino como antecedentes en la toma de decisiones de los funcionarios públicos. Aportan con ello un servicio a los usuarios que acuden a las oficinas 
públicas en busca del reconocimiento de sus derechos y para cumplir con sus obligaciones.

Por tanto, al funcionario y servidor público les asiste una serie de responsabilidades en relación a la conservación, custodia, cuidado y servicio de los documentos. Las responsabilidades que asumen tanto los funcionarios encargados de su custodia como los indirectamente responsables están señaladas en la legislación que rige sobre la materia. Así, tenemos el artículo 21 de la Constitución Política del Perú, el decreto ley 19414, la ley 25323 del SNA, las directivas aprobadas por el AGN, los cuales establecen el tratamiento técnico archivístico que deben recibir los archivos públicos tanto en los procesos técnicos, como en los procedimientos que se derivan de ellos.

En la 36. ${ }^{a}$ Reunión de la Conferencia General de la Unesco, celebrada en el año 2011, se aprobó la Declaración Universal sobre los Archivos, la que establece:

Los archivos custodian decisiones, actuaciones y memoria. Los archivos conservan un patrimonio único e irremplazable que se transmite de generación en generación. Los documentos son gestionados en los archivos desde su origen para preservar su valor y su significado. Los documentos son fuentes fiables de información que garantizan la seguridad y la transparencia de las actuaciones administrativas. Juegan un papel esencial en el desarrollo de la sociedad contribuyendo a la constitución y salvaguarda de la memoria individual y colectiva. El libre acceso a los archivos enriquece nuestro conocimiento de la sociedad, promueve la democracia, protege los derechos de los ciudadanos y mejora la calidad de vida. (2012) 
La declaración reconoce el carácter único e irremplazable de los archivos. De igual forma, denota su relevancia en relación con la transparencia de la información a la salvaguarda de la memoria histórica y su papel frente a los valores democráticos de protección de los derechos de los ciudadanos.

En 2013, la Open Society Foundations reunió a organizaciones y expertos de setenta países que redactaron los llamados "Principios globales sobre seguridad nacional y el derecho a la información" o simplemente "Principios de Tshwane". El documento aprobado contiene cincuenta principios, de los cuales ha de resaltarse el número 15: "Las autoridades públicas tienen la obligación gestionar, archivar y custodiar adecuadamente los documentos; los sistemas de archivos deben ser congruentes, transparentes (cautelando por la reserva de la información clasificada) y exhaustivos, de forma que los documentos puedan ser fácilmente localizables" (pp. 35, 36).

\section{La relevancia de los archivos para el acceso y transparencia de la información}

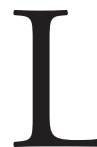

as constituciones de los países del mundo incluyen el derecho a la información, que toma relevancia a partir de la aprobación de la Declaración Universal de los Derechos Humanos. Dicha Declaración lo incluye como uno de los derechos fundamentales del hombre (artículo 19) y destaca de esta manera la importancia de la información como uno de los soportes de la democracia que permite al ciudadano participar e incorporarse en el desarrollo de ella y en su futuro.

A partir de dicha declaración, este derecho forma parte de la ley de máximo nivel de los estados del mundo. Aunque, si revisamos el cumplimiento estricto de su alcance, llegaríamos a la conclusión que no 
basta con legislar sobre la materia, sino que existe la necesidad de que la sociedad civil se implique en el proceso, por jugar un rol fundamental en su cumplimiento. Además, la consecución cabal de este derecho pasa por disponer de información fiable, accesible y totalmente entendible, la misma que debe ser o es custodiada por los archivos. Bertoni y Torres, en conjunción con lo anterior, señalan:

Como sabemos, las legislaciones no operan en el vacío, sino en un complejo entramado de instituciones, reglas y actores. Si bien los principios y estándares internacionales son clave para promover y mejores legislaciones, la consideración del contexto en el que estas operan es vital para asegurar la implementación de las leyes. El acceso a la información no es ajeno a esta regla general. Su implementación ha demostrado que pueden aparecer muchos obstáculos y contratiempos. Algunos provienen del mismo texto de las leyes; otros provienen de la distancia que existe entre los principios consagrados por las normas y la realidad organizacional de las instituciones que deben abrir sus documentos. Dentro de este último grupo de problemas se destaca la falta de consideración de la gestión documental, un área que generalmente ha sido descuidada dentro de la administración pública y postergada en la promoción del derecho a saber. (2014, p. 7; las cursivas son nuestras)

Los autores señalan con acierto que no es suficiente contar con una legislación a veces moderna y ejemplar, sino también tenemos que mirar el contexto para saber qué factores conllevan a que no se cumplan o se 
soslayen. Advierten que uno de esos factores lo constituye el desdén de las autoridades y el desconocimiento de la población acerca de los archivos.

En diversos foros y congresos internaciones sobre archivos, acceso a la información, transparencia y rendición de cuentas, se señala con acierto que los resultados o éxito del gobierno abierto se fundamenta en procurar que la creación y conservación de documentos íntegros, confiables y auténticos sea evidencia de los actos, transacciones y acciones, así como de las políticas del gobierno. En cuanto a los ciudadanos, se apela a que tengan la posibilidad de acceder sin reparos a esa información que le servirá para proteger sus derechos y avizorar o evaluar lo que las administraciones realizan. Casadesús (2018) señala algunas consideraciones sobre el tema:

Para facilitar la transparencia, así como para aumentar la confianza en los procesos de rendición de cuentas se necesita disponer de un sistema que sea capaz de permitir y facilitar la localización de la información y los documentos de la organización. Esto puede ser realidad cuando se hayan implantado sistemas de gestión documental en las administraciones públicas, ya que únicamente a través de la normalización en los procesos de gestión de documentos se puede disponer de información fácilmente recuperable, además de integra, fiable y usable. De nada sirve poder acceder a un documento si no puede visualizarse (usabilidad), si la información contenida ha sido alterada (integridad), si el documento es incompleto o contiene informaciones falsas (fiabilidad) o si el documento no tiene garantía de autenticidad (que haya sido creado por quien dice que lo ha creado y qué momento lo ha creado). En cualquiera de estas situaciones ni la transparencia ni la rendición de cuentas quedarían satisfechas. (2018, p. 124) 
Entonces, el proceso necesita que los servidores y funcionarios tomen conciencia y asuman que los documentos deben estar al servicio de los ciudadanos. Para ello será importante, conjuntamente con las leyes apropiadas, la adopción de medidas adicionales que cambien la manera de pensar del servidor público, desde el punto de vista ético y de la responsabilidad.

El cumplimiento de este derecho fundamental de acceso a la información — recogido en la Constitución de 1993 (artículo 2, numeral 5)—, expresa el derecho de la persona:

A solicitar sin expresión de causa la información que requiera y a recibirla de cualquier entidad pública, en el plazo legal, con el costo que suponga el pedido. Se exceptúan las informaciones que afectan la intimidad personal y las que expresamente se excluyen por ley o por razones de seguridad nacional.

Posteriormente este precepto constitucional es plasmado en la Ley 27806 de transparencia y acceso a la información pública, que a la fecha presenta algunas modificatorias. De igual modo, la Constitución Política del Perú, en su artículo 39, dice: "Todos los funcionarios y trabajadores públicos están al servicio de la Nación. El presidente tiene la más alta jerarquía...”. Por su parte, el artículo 41 indica:

Los funcionarios y servidores públicos que señala la ley o que administran o manejan fondos del Estado o de organismos sostenidos por este deben hacer declaración jurada de bienes y rentas al tomar posesión de sus cargos, durante su ejercicio y al cesar en los mismos... Cuando se presume enriquecimiento 
ilícito, el Fiscal de la Nación, por denuncia de terceros o de oficio, formula cargos ante el Poder Judicial. La ley establece la responsabilidad de los funcionarios y servidores públicos, así como el plazo de inhabilitación para la función pública. El plazo de prescripción se duplica en caso de delitos cometidos contra el patrimonio del Estado.

Estos derechos de la ciudadanía se reafirman en los lineamientos de políticas públicas y de Estado a través del Acuerdo Nacional, que señala la importancia de reafirmar la identidad nacional, contar con un Estado eficiente y transparente que permita la ética y la erradicación de la corrupción y, por supuesto, el acceso a la información. Dichos lineamientos están presentes también en el Plan Estratégico de Desarrollo Nacional —llamado "Plan Bicentenario: el Perú hacia el 2021"—, que establece los objetivos nacionales. Tales objetivos contemplan la plena vigencia de los derechos fundamentales y de dignidad de las personas, la sociedad del conocimiento, así como un Estado eficiente y descentralizado al servicio de los ciudadanos y del desarrollo.

Sabemos que los documentos informan y comunican los hechos realizados en el ejercicio de las funciones de los empleados públicos, además de evidenciar los actos y actividades del aparato estatal. Por tanto, los documentos son muy importantes en la función pública cuando se trata del acceso a la información, la transparencia y la rendición de cuentas. Lamentablemente, en muchas ocasiones, las denuncias sobre la desaparición de documentos se repiten sin tener fin, con lo que se priva a la sociedad de su derecho a informarse. 
También es conocido que las acciones aisladas para el fomento de la transparencia e integridad producen resultados insatisfactorios y mínimos si se tiene en cuenta la magnitud de las consecuencias que afectan a la sociedad. De igual manera, por la aplicación de nuevas tecnologías para el fomento de la transparencia, a la par de la inmensa cantidad de información que por los medios informáticos se procesa, también se produjo en muchos casos la pérdida de grandes cantidades de información por la fragilidad y facilidad con que se puede vulnerar la seguridad de los medios informáticos. El resultado ha sido la desaparición de gran cantidad de documentos.

Para que los sistemas transparentes funcionen, será necesario propiciar un diferente accionar de los funcionarios. Esto con el objetivo que dejen de ser un obstáculo en el desarrollo y progreso de la democracia, donde la transparencia sea efectiva y se cuente con archivos organizados de fácil acceso a la información para tener a disposición los documentos que sustentan la gestión administrativa.

Como podemos apreciar, las responsabilidades en la función pública se encuentran legisladas desde el más alto nivel normativo. A partir de la Constitución Política, se aprobó una serie de normas de carácter penal y administrativo que precisan las responsabilidades y sanciones que son de aplicación a los funcionarios y trabajadores del Estado cuando comenten faltas o delitos durante el ejercicio de sus funciones. Así, desde que surge el concepto de Estado, los hombres que lo sirven se comprometen a conducirse de acuerdo con las leyes y bajo principios éticos.

La transparencia y la rendición de cuentas son dos conceptos que están estrechamente vinculados a los documentos como producto de la función pública. Son ellos los instrumentos que podrán hacer viables ambas acciones desde el momento que se ponen a disposición de las autoridades 
o ciudadanos, ya que evidencian los actos y actividades realizadas en el ejercicio de la función pública.

En consecuencia, vemos la importancia que los procesos y los instrumentos de gestión documental tienen, vinculados de manera indubitable con la transparencia y las acciones de rendición de cuentas. Esto se podrá conseguir a partir de la implementación, desarrollo y mejora de los sistemas de gestión documental, que incluyen en su accionar ambos procesos (Casadesús, 2018, p. 127). El diseño de dichos sistemas debe comprenderse más allá de la gestión interna para poder asegurar que la información pública llegue a los ciudadanos y se garantice su autenticidad, integridad, trazabilidad y reutilización.

Alberch destaca la necesidad de que el acceso a los documentos sea regulado para hacerlos compatibles con la libre determinación del ciudadano de informarse en un Estado democrático. Esta regulación se da en las últimas décadas gracias a la aprobación de leyes sobre transparencia y rendición de cuentas que permiten a los ciudadanos mantenerse vigilantes del accionar del Estado, lo que es una garantía para mantener la seguridad jurídica:

Concienciarse de la necesidad de regular el acceso a los documentos y a la información contenida en los archivos para hacer compatibles los derechos democráticos de libre acceso, transparencia administrativa y participación ciudadana con la garantía de preservar la intimidad de los ciudadanos. (Alberch, 2003, p. 16)

No obstante, el autor advierte que el acceso debe ser compatible con el derecho de los ciudadanos a proteger su intimidad personal. Por tanto, 
si bien es un derecho constitucional del ciudadano (para el caso peruano, contemplado en el artículo 2, inciso 5), está sujeto a normativa especializada que señala sus restricciones cuando pone en riesgo el derecho a preservar la intimidad personal.

De la Carta de Derechos Fundamentales de la Unión Europea (2010), aprobada en Niza, ha de resaltarse el artículo 42 sobre el Derecho de acceso a los documentos. De acuerdo con este, todo ciudadano de la Unión y toda persona física o jurídica que resida o tenga su domicilio social en un Estado miembro tiene derecho a acceder a los documentos de las instituciones, órganos y organismos de la Unión, cualquiera que sea su soporte. (Diario Oficial de la U. E., 2010 p. C83/399). Rodríguez-Arana (2014, p. 28) en su comentario sobre la Carta Europea líneas arriba indicada, señala, sobre la base de lo explicitado en referida carta (derecho fundamental general de los ciudadanos), que existen otros derechos que lo componen, los cuales las personas podrán reclamar en el fuero administrativo o judicial. De los 31 derechos que anota el autor, se destaca el signado con el número 20: "Derecho a una ordenación racional y eficaz de los archivos públicos". El numeral 23 remarca no solo el derecho al acceso de los ciudadanos a los documentos y archivos administrativos, sino también a ser informado y asesorado en asuntos de interés general.

Es menester destacar que el autor se refiere a que el acceso a la información solo es posible si se mantienen archivos ordenados, los cuales permitan la accesibilidad a ellos. De la misma manera, menciona la necesidad de realizar una ordenación racional de los archivos públicos, lo que se traduce en un tratamiento archivístico que contemple las técnicas propias de archivo. Esto posibilitará un acceso real a la información contenida en los 
archivos públicos, donde la aplicación de las TIC contribuya a una eficiente y eficaz atención archivística (Rodríguez-Arana, 2014, p. 54).

El Perú está inmerso en un proceso de modernización de la Administración Pública. Según López y Chang:

El proceso de modernización del Estado se sustenta, fundamentalmente, en la priorización de la labor de desarrollo social en beneficio de los sectores menos favorecidos mejorando, entre otras acciones, la prestación de los servicios públicos; impulsando la concertación, con la participación de la sociedad civil y las fuerzas políticas, diseñando una visión compartida y planes multianuales, estratégicos y sustentables; y promoviendo la descentralización a través del fortalecimiento de los Gobiernos locales y Regionales; e institucionalizando la evaluación de la gestión por resultados a través del uso de modernos recursos tecnológicos, la planificación estratégica concertada, la rendición pública y periódica de cuentas y la transparencia a fin de garantizar canales que permitan el control de las acciones del Estado. (2007, p. C5)

Por otro lado, el Quinto Pilar de la Política de Modernización Pública al 2021, aprobado por decreto supremo 004-2013-PCM —referido al sistema de información, seguimiento, monitoreo, evaluación y gestión de conocimiento-, se entiende como el sistema de información que incluye uno de gestión documental que necesariamente debe constituirse en cada organismo público respecto del tratamiento de los documentos producidos por las diversas unidades orgánicas que lo conforman como resultado de sus actividades administrativas y que constituyen patrimonio documental de la 
nación, según el decreto supremo 022-75-ED, reglamento del decreto ley 19414 (artículo 2, segundo párrafo).

Andía (2019) se refiere al principio ciudadano-cliente con derechos definidos que el Estado debe satisfacer y proteger de acuerdo con su responsabilidad tuitiva. Luego hace referencia al nuevo perfil del funcionario público, donde la búsqueda de resultados es el centro de atención para la satisfacción ciudadana, asociado a la rendición de cuentas que todo funcionario público está en la obligación de satisfacer. Para ello, los países adoptan normas de transparencia siempre vinculada a la rendición de cuentas en la que se mueve un Estado moderno, cuyos actores de gestión (los funcionarios públicos) son capaces de demostrar rigurosamente cómo realizaron su labor y cómo se ejecutó el gasto público. Rendir cuentas significa demostrar que se actuó con transparencia y en apego a la normativa vigente. Alcanzar estos objetivos con visión de futuro requiere de un Estado moderno con sistemas administrativos transversales y de apoyo. Estos tienen la misión de realizar las tareas rutinarias y de articulación en el cumplimiento de las actividades del sector público. Para ello cuentan con un marco legal que todas las instituciones públicas deben cumplir, pues se trata de reglas generales de funcionamiento o ejecución.

\section{Los sistemas de archivo institucional}

$7 \mathrm{n}$ la revisión de la bibliografía sobre archivística, y desde una mirada a la historia de los archivos, aparece el concepto de "sistemas archivísticos". Este surge en la segunda mitad del siglo XX y tiene su origen en la necesidad que tienen los países latinoamericanos de, en primer lugar, rescatar su legado documental que, durante muchos ańos de olvido, estuvo hacinado en condiciones muchas veces adversas. En segundo 
lugar, se tenía la evidencia de que no se hacía nada por los archivos que la Administración Pública producía y guardaba sin tener un mínimo matiz técnico archivístico que asegurara su conservación y, sobre todo, su puesta en servicio para satisfacer tanto las necesidades de información del ciudadano común y corriente como de la propia administración. Ante esa realidad es que surgen los sistemas de archivo como una forma de enfrentar el problema y lograr un tratamiento archivístico no solo adecuado, sino homogéneo en todos los ámbitos y estamentos de la Administración Pública de cada país.

En ese sentido, Heredia es muy aleccionadora al considerar que "un sistema de archivo está constituido por un conjunto de actividades articuladas a través de una red de centros y servicios técnicos para estructurar la transferencia, recepción, depósito, ordenamiento y descripción y entrega de documentos" (1993, p. 207). Por su lado, Jardim refiere a Vásquez (1994) para destacar la importancia de los sistemas de archivo como instrumentos de racionalización archivística, ya sean nacionales, estatales, municipales, de instituciones estatales o empresas privadas. Desde su perspectiva, un "sistema integrado de archivos es un conjunto orgánico de archivos, vinculados a una dirección central, la cual normaliza los procesos archivísticos y centra la información en un punto accesible a la consulta interna y externa” (2010 p. 174).

Otra definición la encontramos en Cruz Mundet, quien afirma que los sistemas archivísticos son el "conjunto de normas, órganos, centros y servicios, responsable de la gestión eficaz de los documentos y de los archivos" (2011, p. 328). Efectivamente, lo que se busca con la articulación de los sistemas de archivo es asegurar su tratamiento uniforme. También se aspira a que no esté supeditado a criterios subjetivos, muchas veces bien 
intencionados, de personas que asumen la responsabilidad de conducirlos sin tener los conocimientos necesarios para afrontar tal tarea.

Según Jardim: "La literatura y la práctica archivística nos ofrecen diferentes ejemplos de sistemas como objetos de estudio en diversos contextos organizacionales locales, nacionales e internacionales" (2010, p. 139). El autor añade que usualmente se puede encontrar términos como "sistemas de archivo", "sistemas de información de archivo", "sistema de gestión de documentos", entre otros. Para Vicenta Cortés — mencionada por Núnez (1999, p. 140)—, las claves para llevar adelante un buen sistema archivístico son: a) un marco legal que establezca tanto la estructura y los aspectos técnicos, como la transferencia, servicio, etc.; b) recursos humanos capacitados y materiales suficientes; c) normalización de principios y procesos; d) especialización de funciones; y e) aplicación de las tecnologías.

Estos conceptos se asumieron en todas las legislaciones archivísticas de América Latina, de tal suerte que no solo se refieren a "sistemas archivísticos" en general, sino que hay una profusa legislación y literatura que analiza y explica la razón de ser de:

- El Sistema Nacional de Archivos.

- Los sistemas institucionales de archivo.

- Los sistemas de gestión documental.

- Los sistemas de gestión electrónica de documentos de archivo.

- Los sistemas de archivos locales.

- Los sistemas de archivos municipales, universitarios, militares, etc.

No hay duda de que, de todos ellos, el de mayor trascendencia e importancia lo constituye el Sistema Nacional de Archivos. Este, por tener 
aplicación nacional y comprender toda la administración en sus diversas formas y estructuras, integra también aquellos archivos privados que por su trascendencia se adhieren voluntariamente a él.

\section{El sistema nacional de archivos}

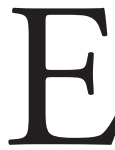

n la mayoría de los países de América Latina, durante el siglo XIX, se crearon los archivos nacionales (por ejemplo, Costa Rica, 1881; México, 1823; Perú, 1861; Uruguay, 1827). Ya en los años setenta y ochenta del siglo XX, la situación de los archivos nacionales no era la óptima. Según Llansó:

Los Archivos Nacionales seguían constituidos exclusivamente como archivos históricos, «atados al más puro clasicismo archivístico», en muchos casos incompletos por insuficiencia de espacio, lo que contribuyó a que se vieran considerados como instituciones creadas para los eruditos, incapaces de normar y regular la gestión de documentos producidos por la administración. (Llansó, 2006, p. 64)

Los archivos nacionales en América Latina vivían a espaldas de lo que constituía el desarrollo archivístico a nivel internacional. En particular, ignoraban los avances de la archivística norteamericana con su aporte del concepto del ciclo vital del documento. Esto último lo trae a la memoria Núñez:

El principio del ciclo vital del documento es consecuencia directa de la experiencia norteamericana en la organización y gestión de archivos a partir de la II Guerra Mundial. Al intervenir 
directamente en las fases de gestión y producción de los documentos de la gran administración federal norteamericana para poder llevar a cabo la planificación completa del proceso documental hasta su recepción en los archivos históricos, los profesionales norteamericanos se percataron de la evidencia de este ciclo y de su trascendencia en la organización de los fondos: un solo fondo, varias fases. (Núñez, 1999, p. 136)

Las estructuras y el concepto de sistemas nacionales de archivo en América Latina se desarrollan teniendo como referencia el modelo NATIS. Tal como manifiesta Jardim, sobre la base del modelo NATIS, la Unesco publicó, en 1974, la obra de Delmas y D’Olier “La planificación de las infraestructuras nacionales de documentación, bibliotecas y archivos: esbozo de una politica general'. Específicamente en lo que a archivos se refiere, las prolongaciones del NATIS propuestas por Delmas van a influir hasta comienzos de los años ochenta en las diversas acciones de la consultoría técnica de la Unesco al implantar Sistemas Nacionales de Archivo en países latinoamericanos y africanos (Jardim, 2010, p. 168).

El llamado modelo NATIS surge de la Conferencia Intergubernamental sobre el Planeamiento de las Infraestructuras Nacionales de Documentación, Bibliotecas y Archivos, celebrada en París el año 1974. Su nombre se utilizó para designar los sistemas nacionales de información. Con el apoyo de Unesco (1976) a los países latinoamericanos, luego de un examen de la situación de la información, se planteó la creación de los sistemas nacionales de archivos.

Según Llansó, la paulatina evolución que se ha observado en la definición de los Sistemas Nacionales de Archivos en Iberoamérica tiene sus orígenes en la Primera Reunión Interamericana sobre Archivos (Washington, 
octubre de 1961). En dicho evento se acordó una serie de pautas comunes para la coordinación de disposiciones legislativas: estas debían establecer los fondos documentales que debían conservarse, normalizar de forma liberal el acceso a documentos públicos de antigüedad inferior a 30 años y establecer procedimientos para la gestión de documentos administrativos y archivos intermedios, entre otros (Llansó, 2006, p. 62). También cabe mencionar otros eventos de singular importancia, por cuanto en ellos se establecieron las pautas o bases para el reconocimiento del patrimonio documental de la nación y el inicio de una nueva era en la archivística de América Latina:

- Reunión Técnica sobre Desarrollo de Archivos (Washington DC, julio de 1972), que tiene como resultado la "Carta de Archivos".

- Seminario Multinacional sobre Planificación y Reorganización de Archivos Nacionales, organizado por la Organización de Estados Americanos (Lima 1973).

- Grupo de Trabajo de la Asociación Latinoamericana de Archivos (ALA) y el Comité de Archivos del IPGH (Instituto Panamericano de Geografía), con representantes de Brasil, Canadá, España, México, Perú y EE. UU. (1986). Sobre los resultados de este grupo, Llansó — citando a Chacón et al._ dice: "Se consideró allí que un Sistema Nacional de Archivos, como conjunto de todos los archivos de un país, reunidos en virtud de una ley bajo una unidad de régimen, era la mejor forma de organizarlos, para la mayor eficacia de sus funciones y servicios' (1993: 135-144)" (2006, p. 62). Jardim, citando a Delmas, dice: "El concepto de sistema nacional de archivos según Delmas (ibid.), abarca el conjunto de fondos documentales, públicos y privados existentes en el territorio nacional. El estudio de un sistema nacional de archivos debe tener 
en cuenta: la forma centralizada o descentralizada de la estructura del Estado; el grado de autonomía de las autoridades regionales y locales; el poder de intervención de la administración central en los asuntos locales, la situación social del país, etcétera" (Jardim, 2010, p. 169).

Durand (1984) precisa con mucha claridad que el SNA es la integración de todos los archivos de la Administración Pública con autoridad sobre los documentos producidos de la gestión pública, cualquiera sea la procedencia de los documentos: ministerios, municipalidades, organismos autónomos, judiciales, legislativos, etc.

El mismo autor explica por qué es sistema y por quéla denominación:

Es sistema porque es una organización técnica de archivos, que coordina la actividad, establece normativamente pautas de ordenamiento, en el plano de la especialidad profesional, con una de línea de autoridad jerárquica, que lleva a la unidad de criterio para planificar y establecer una adecuada política archivística. El ámbito de su actividad es nacional que cubre todo el país y abarca todos sectores, organizando directamente, en unos casos controlando o supervigilando y en otros impartiendo normas con autoridad de un archivo es la conservación documental. El documento debe ser custodiado legalmente. (Durand, 1984, p. 12)

Así, la mayoría de los países latinoamericanos se abocan a la tarea de legislar sobre la creación y funcionamiento de un sistema nacional de archivos. En ese contexto, destacan: Brasil, que se constituye como el país 
pionero en crear su SNA (1978), Ecuador (1982), Colombia (1989), Costa Rica (1990), Perú (1991), Cuba (2001), Uruguay (2007) y México, que es un caso singular en tanto, desde la década de los años ochenta, funciona como sistema, pero legalmente se da en 2018.

Para efectos de esta investigación, se seleccionó países como Colombia, Costa Rica, México, Uruguay y Perú con el fin de dar un acercamiento a su realidad archivística. Se tomará como referencia las diversas leyes sobre la materia que permiten el funcionamiento de los archivos nacionales, llamados también en algunos países "archivos generales de la nación”. A la legislación correspondiente se accede a través de los portales web de los archivos nacionales de los países. En consecuencia, del estudio realizado podemos establecer algunas consideraciones:

- Los países estudiados tienen en común que las leyes de creación de sus archivos nacionales sean muy antiguas. Tal es el caso de Costa Rica (1881), México (1823), Perú (1861) y Uruguay (1926). Colombia es la excepción, ya que su ley es de 1989.

- A partir de la década de los años ochenta, se inicia en América Latina un proceso por el cual se comienza a establecer los SNA como entidad que integra de manera estructural, funcional $y$ normativa los archivos públicos de cada país. Todos los países analizados tienen como sujetos obligados a todas las instituciones comprendidas en los poderes del Estado.

- Los países estudiados asignan la obligación de velar por su cumplimiento y conducción a un organismo público especializado, como son los archivos nacionales. En el Perú, ese rol está asignado al AGN. 
- En todos los casos se establece la capacidad de emitir normas archivísticas, así como la supervisión y control de los órganos encargados o rectores. No se otorga capacidad sancionadora; aunque, en el caso de Perú, se establece cuáles son las acciones o conductas prohibidas.

- Los países comprendidos en este estudio se preocuparon por incorporar a su legislación el documento electrónico.

En ese sentido, México es el único país que explícitamente, tanto en su Constitución como en el cuerpo legislativo archivístico, incorpora el proceso de gestión documental y el valor del documento de archivo, además de reconocer el documento electrónico como tal. Países como Colombia, Costa Rica y Uruguay avanzaron en menor medida. En el caso de Perú, hasta la fecha no se incorpora el documento electrónico ni la gestión documental en su legislación archivística.

Scarensi precisa que la existencia de Sistemas Nacionales de Archivos podría contribuir a satisfacer la necesidad de administrar, coordinar, asesorar y supervisar los archivos de una nación, ya que se contemplaría acciones coordinadas de los archivos públicos y privados -que decidan sumarseexistentes en el país, vinculados y articulados en forma tal que sus recursos y servicios puedan ser aprovechados por la comunidad, incluyendo políticas de difusión del patrimonio documental haciendo efectivo el derecho a la información por parte de los ciudadanos (Scarensi, 2014, p. 152).

Por lo tanto, la puesta en marcha de los sistemas nacionales de archivo, en cumplimiento de un conjunto de políticas que tengan por objetivo establecer las herramientas que permitan el accionar, desarrollo y reconocimiento de los archivos en los países, deberá ser garantizada por un 
marco legal. Asimismo, este debe ir en armonía con las acciones destinadas al ejercicio cabal del derecho de acceso a la información, la transparencia y la rendición de cuentas. En ese sentido, se debe dejar establecido que la legislación archivística debe contar con los siguientes puntos para lograr su cometido (Scarensi, 2014, p. 153):

- Contar con infraestructura y presupuesto.

- Aplicar la moderna disciplina archivística respeto a los principios archivísticos, el ciclo vital de los documentos, los procesos técnicos archivísticos y la conservación preventiva.

- Procurar herramientas a los integrantes del SNA que aseguren la preservación de los documentos en tanto garantía de los derechos de los ciudadanos.

- Los SNA deben contar con un ente rector que lidere el sistema y sea provisto de autonomía administrativa y financiera que permita el cumplimiento de sus objetivos y funciones. - Establecer las pautas precisas para la gestión documental de acuerdo al ciclo vital de los documentos en toda la Administración Pública y en sus diversos niveles.

- Cumplir de manera obligatoria todas las normas técnicas que emita el SNA y que apruebe el órgano rector.

- Fijar reglas precisas de clasificación y desclasificación de la información por series documentales y establecer plazos para facilitar el acceso a los documentos.

- Elaborar guías de atención a usuarios. Finalmente, la revisión de la legislación en países de América Latina nos permite apreciar cómo la aprobación de leyes del SNA y de archivos se inicia en los ańos ochenta. Pero estos países, en años recientes, se abocaron 
de manera paulatina a emitir nuevas leyes que incorporaran los aspectos relevantes de la archivística de los últimos tiempos a su normatividad. Este proceso no se da en el Perú, cuya ley de SNA data de 1991.Esta realidad de la archivística peruana constituye un serio inconveniente que no contribuye al desarrollo de los archivos, pues se carece de los elementos legales o normativos que le permitan ser tomados en cuenta y desarrollarse para el beneficio del país.

La situación de los archivos públicos en el Perú es crítica y se vio agudizada en los últimos años. Esta situación se puede describir como un problema de gestión que tiene sus orígenes en el desconocimiento y desfase de la legislación archivística, un SNA casi ausente, el AGN como órgano rector que no cumple a cabalidad sus funciones, la carencia de personal profesional y la insuficiente oferta de formación superior especializada en archivística. No hay que dejar de mencionar la ausencia de una política de gestión documental que contemple los fundamentos archivísticos y sus herramientas, así también, la indiferencia de los gobiernos sobre la situación de los archivos.

\section{Conclusiones}

- Actualización de la legislación archivística y normatividad técnica

En el contexto internacional, la mayoría de los países de América Latina procuran incluir en sus legislaciones las disposiciones que les permitan afrontar los retos de la archivística moderna en sus países. El Perú se encuentra rezagado, ya que no actualizó su legislación archivística en aspectos como la gestión documental, el documento electrónico, la transparencia y rendición 
de cuentas, el gobierno abierto, la profesionalización del archivero y el uso de las tecnologías de la información y comunicación.

De acuerdo con lo anterior, la legislación archivística y las normas técnicas peruanas requieren actualización. La ley del SNA es de 1991 y las normas técnicas se aprobaron en 1986. Asimismo, las normas archivísticas emitidas durantelos años 2018 y 2019 no incorporan los cambios archivísticos necesarios, lo cual no se condice con el proceso de modernización de la Administración Pública en curso. De igual forma, es importante definir las competencias del AGN en el proceso de modernización de la Administración Pública.

La legislación archivística, por tanto, contempla las obligaciones o deberes que necesariamente se han de realizar, el servicio a la investigación y el servicio a los ciudadanos como funciones fundamentales de los archivos. Además, hace referencia al funcionamiento del archivo propiamente, la accesibilidad, la transparencia, la gestión documental y el cumplimiento de las normas técnicas correspondientes a los diferentes procesos de archivo. Para lograr estos cometidos, es preciso una legislación archivística coherente y actualizada. La actualización de la legislación archivística alude al proceso y consecuencia de actualizar, es decir, lograr que esté al día de acuerdo con los tiempos actuales.

- Modernización de los archivos públicos

Los archivos públicos sufren de limitaciones y no son atendidos adecuadamente por las autoridades y gobiernos de turno. El presupuesto escaso, los locales inadecuados, el personal improvisado, la debilidad del SNA, la opacidad en la actuación del AGN, la legislación archivística desactualizada y la desorganización de los archivos es consecuencia de ello. Mientras subsistan estos problemas, se hará difícil la modernización de los 
archivos y no podrán cumplir con los objetivos de conservación, servicio y accesibilidad que deben tener.

Transformar la estructura y el funcionamiento de los archivos hasta el punto en que se asemejen a los archivos modernos del mundo. En ese sentido, estamos en un proceso de modernización de la Administración Pública en el que los ciudadanos exigen al Estado que los servicios que brindan sus entidades sean eficientes y eficaces, además que los archivos son parte de ellos por ser responsables de la custodia y puesta al servicio de la información que los ciudadanos requieren, en cumplimiento de las normas establecidas.

- Definición del SNA como sistema administrativo en el ámbito de la Administración Pública

Según Rubio: "Un sistema es la suma organizada de normas, órganos y procesos destinados a proveer a la administración pública de los insumos necesarios para cumplir eficientemente sus fines institucionales... no es un organismo sino un concepto en el que se comprende a varios elementos, entre los que se cuentan distintos organismos públicos" (2009, p. 67). Por lo tanto, cuando la administración pública se organiza para desarrollar sus funciones y cumplir sus objetivos, lo hace a través de sistemas administrativos o funcionales. Estos están constituidos por un órgano rector, principios, normas, procesos y procedimientos.

En este contexto, existe el Sistema Nacional de Archivo que procura la integración de los archivos en un determinado país, lo que permite su desarrollo y modernización en función de las políticas archivísticas establecidas y procesos técnicos archivísticos normalizados. Por ello, se debe procurar su afianzamiento como sistema administrativo en el ámbito de la Administración Pública en aras de contar con archivos eficientes y eficaces 
que apoyen el proceso democrático de acceso a la información, el gobierno abierto, la transparencia de la información y la rendición de cuentas. Ahí el proceso de gestión documental debe contemplar no solo la producción de documentos, sino todo su ciclo vital, porque serán integrantes del patrimonio documental de la nación. Por lo tanto, en el Estado se debe propender a este objetivo y reconocer el SNA como un sistema administrativo en la estructura de la Administración Pública.

- Reestructuración y fortalecimiento del AGN como órgano rector del SNA

La normativa archivística establece la existencia del AGN como órgano rector del SNA y, como tal, debe asumir la función de liderazgo de los archivos en el país con la misión de emitir normas y vigilar su cumplimento. La investigación permite constatar que el AGN no cumple con las funciones que tiene establecidas. Se aprecia un abandono del SNA y, de acuerdo con los especialistas entrevistados, esto se debe a la improvisación de autoridades, el insuficiente presupuesto que le permita atender sus principales necesidades como un local adecuado para el AGN y la carencia de personal altamente calificado en materia archivística.

El AGN es una institución adscrita al Ministerio de Cultura. En él se custodian documentos que datan del siglo XVI hasta la actualidad. A su vez, es el organismo que lidera el SNA y tiene la misión de proponer y ejecutar las políticas archivísticas de protección, organización y servicio del patrimonio documental de la nación. Su reestructuración y fortalecimiento consiste en cambios en su estructura y funciones, además de otros aspectos, que le permitan cumplir a cabalidad con las funciones que ya tiene asignadas, así como otras que en los actuales momentos debe asumir y que no comprende su accionar por las graves deficiencias de diversa índole que hoy dificultan su 
buen funcionamiento. Por ello, se entiende aquí la reestructuración como el proceso de modificación de la estructura (reordenamiento o reorganización) del AGN, que las actuales circunstancias hacen necesaria para lograr mejores resultados a los que se vienen observando. Aunque, a su vez, se requiere del fortalecimiento institucional, entendiéndose esto como la mejora de la eficiencia y la eficacia.

\section{REFERENCIAS}

Alberch, R. (2003). Los archivos, entre la memoria histórica y la sociedad de la información. UOC.

Ampudia, J. E. (1988). Institucionalidad y gobierno: un ensayo sobre la dimensión de la administración pública. Instituto Nacional de Administración Pública.

Andía, W. (2019). Manual de gestión pública: Pautas para la aplicación de los sistemas administrativos. Arte \& Pluma.

Archivo General de la Nación. (2016). II Censo nacional de Archivos - 2014. Resultados definitivos. Entidades públicas, notarias, arzobispados y obispados. Archivo General de la Nación.

Bertoni, E. \& Torres, N. (2014). Introducción. En N. Torres (comp.), Hacia una politica integral de gestión de la información pública: todo lo que siempre quisimos saber sobre archivos (pp. 7-10). Universidad de Palermo. https://www.palermo.edu/cele/pdf/Hacia_una_politica_ integral-kk.pdf 
Casadesús, A. (2018). La gestión de riesgo aplicada a la gestión de documentos y su impacto en la rendición de cuentas pública [Tesis para optar el grado de Doctor en Historia comparada política y social]. Universitat Autónoma de Barcelona. https://www.tdx.cat/ handle/10803/665386\#page $=1$

Cruz Mundet, J. R. (2011). Archivistica: gestión de documentosy administración de archivos. Alianza Editorial.

Diario Oficial dela Unión Europea. (2010). Carta de los derechosfundamentales de la Unión Europea. https://www.boe.es/doue/2010/083/Z0038900403.pdf

Durand, G. (1984). Sistema Nacional de Archivos. Revista del Archivo General de la Nación, 7, 11-47.

Jardim, J. M. (2010). Politicas y sistemas de archivo. Secretaria General Iberoamericana - Red de Archivos Diplomáticos Iberoamericanos.

Heredia, A. (1993). Archivistica general, teoría y práctica. Diputación Provincial de Sevilla.

López, J. \& Chang, J. (2007). Planeamiento y presupuesto. Revista de Gestión Pública, C5- C10.

Llansó, J. (2006). Sistemas archivísticos y modelos de gestión de documentos en el ámbito internacional (Parte 1). Revista Códice, 2(1), 53-88. http://eprints.rclis.org/20305/1/Sistemas\%20 archiv \% C 3\% ADsticos \% 20 y $\% 20$ modelos $\% 20 \mathrm{de} \% 20$ gesti $\%$ C3\%B3n\%20de\%20documentos\%20en \%20el\%20 \%C3\%A1 mbito\%20internacional\%20\%28Parte\%201\%29.pdf 
Mendoza N., A. (2015). El sistema institucional de archivos. Lima: Secretaría General Iberoamericana - Red de Archivos Diplomáticos Iberoamericanos.

Nazar, M. (2014). El acceso a los archivos: sistemas de gestión de la información implementados en América Latina. En N. Torres (comp.), Hacia una politica integral de gestión de la información pública: todo lo que siempre quisimos saber sobre archivos (pp. 1146). Universidad de Palermo. https://www.palermo.edu/cele/pdf/ Hacia_una_politica_integral-kk.pdf

Nazar, M. (2017). Archivos y derechos humanos: entre la historia, la memoria y la justicia. En J. Vasallo \& S. Brunero (coords.), El acceso a los archivos en la sociedad del conocimiento. Apreciaciones desde la Argentina del siglo XXI (pp. 17-45). Red de Graduados de Córdoba.

Núñez, E. (1999). Organización y gestión de archivos. Trea

Open Society Justice Initiative. (2013). Principios globales sobre seguridad nacional y el derecho a la información ("Principios de Tshwane"). Open Society Foundations. https://www.justiceinitiative.org/ publications/global-principles-national-security-and-freedominformation-tshwane-principles/es

Rodríguez-Arana, J. (2014). La buena administración como principio y como derecho fundamental en Europa. Misión Jurídica. Revista de Derecho y Ciencias Sociales, 6(6), 23-56. https://www.revistamisionjuridica. com/wp-content/uploads/2020/09/art1-2.pdf

Rubio, M. (2009). El sistema jurídico. Introducción al Derecho. Fondo Editorial PUCP. 
Scarensi, M. J. (2014). La legislación archivística y el acceso a la información en América Latina. En N. Torres (comp.), Hacia una politica integral de gestión de la información pública: todo lo que siempre quisimos saber sobre archivos (pp. 109-154). Universidad de Palermo. https://www. palermo.edu/cele/pdf/Hacia_una_politica_integral-kk.pdf 